\title{
Fragmentos de identidad local en el cine de ficción rodado en la región del Bío-Bío, Chile*
}

\author{
Fernando Fuente-Alba C. ${ }^{* *}$ \\ Óscar Basulto G.** \\ Shirley Moraga D. ${ }^{* * *}$ \\ Recibido: 2019-02-15 - Enviado a pares: 2019-02-20 \\ Aprobado por pares: 2019-03-28 - Aceptado: 2019-05-20 \\ https://doi.org/10.22395/angr.v18n35a6
}

\begin{abstract}
Resumen
Esta investigación tiene por objetivo general conocer fragmentos identitarios de la región del Bío-Bío en Chile, que están presentes en el cine de ficción rodado en la zona entre 2010 y 2017. A nivel específico, se busca indagar sobre la contribución del cine en la construcción de identidad local, así como jerarquizar los rasgos identitarios detectados en la muestra fílmica. La metodología empleada identificó la producción cinematográfica de la región, para luego indagar sobre posibles rasgos que de algún modo pudieran caracterizar a la comunidad local en el periodo de tiempo señalado. Para ello se tuvo en consideración el contenido de las películas analizadas; y se realizaron una entrevista grupal y entrevistas individuales con fuentes expertas e informantes clave, respectivamente, cuyos hallazgos se contrastaron con un estudio documental que brinda una contextualización en el ámbito local. Asimismo, se utilizó teoría sobre identidad para dar sustento epistémico al desafío planteado en los objetivos. Finalmente, se analizó la presencia o ausencia de rasgos identitarios en la muestra fílmica mediante la observación directa y el análisis de personajes y ambientes: es destacable en este sentido, el hecho de que los rasgos identitarios más recurrentes en el cine analizado son catástrofes naturales, seguidos de los rasgos indígena y campesino. Por otro lado, se determinó que la mayoría de los filmes sí poseen muchos de los posibles rasgos identificados y co-construidos en la zona. Por lo tanto, se concluye que el cine de la región estudiada contribuye en el período analizado a la construcción de una identidad local, a través de la inclusión de fragmentos identitarios específicos que se explicitan en las películas.
\end{abstract}

Palabras clave: cine; identidad; construcción de realidad; rasgos identitarios; significación social; cultura, localidad; Bío-Bío (Chile).

Artículo asociado a proyecto interno financiado por el Departamento de Ciencias de la Comunicación de la Universidad Católica de la Santísima Concepción (Chile).

. Doctor en Comunicación Audiovisual. Académico de la Universidad Católica de la Santísima Concepción y miembro del Departamento de Ciencias de la Comunicación de la Facultad de Comunicación, Historia y Ciencias Sociales, Concepción, Chile. Correo electrónico: ffuentealba@ucsc.cl. Orcid: http://orcid.org/0000-0002-4316-5097

... Doctor en Sociología. Académico de la Universidad Católica de la Santísima Concepción y miembro del Departamento de Ciencias de la Comunicación de la Facultad de Comunicación, Historia y Ciencias Sociales, Concepción, Chile. Correo electrónico: obasulto@ucsc.cl. Orcid: http://orcid.org/0000-0001-8323-1098

.... Periodista, Universidad Católica de la Santísima Concepción, Concepción, Chile. Correo electrónico: smoraga@ periodismo. ucsc.cl. Orcid: http://orcid.org/0000-0002-9033-8296 


\title{
Fragments of Local Identity in Fiction Films Shot in the Region of Bío-Bío, Chile
}

\begin{abstract}
The main objective of the research discussed in this paper was to identify fragments of the Bío-Bío (Chile) region, which are present in fiction films shot in the area between 2010 and 2017. At a specific level, the aim was to study the contribution of cinema in the construction of local identity, as well as hierarchize the identity traits detected in the filmic sample. Through the selected methodology, the cinematographic production of the region was identified, and then possible identity traits that could characterize the local community in a certain period of time were studied. For this purpose, the content of the analyzed films was taken into consideration, a group interview and individual interviews were carried out with expert sources and key informants, respectively, and findings were contrasted with a documentary study that gave a context view at a local level. In turn, identity theory was used to give epistemic support to the challenge posed in the research's objectives. Finally, the presence or absence of identity traits in the film sample was analyzed through direct observation and analysis of characters and environments, and the postulates of apparent and latent content. Among the most important findings, it is worth noting that the most recurrent identity traits in the cinema analyzed were natural catastrophes, followed by the indigenous and peasant traits. On the other hand, it was determined that most of the films do possess many of the identitary features identified and co-constructed in the area. Therefore, it can be concluded that in the analyzed time period, the cinema of the Bío-Bío region contributed to the construction of a local identity through the inclusion of specific identity fragments, which were explicit in the films.
\end{abstract}

Keywords: cinema; identity; construction of reality; identity traits; social significance; culture; locality; Bío-Bío (Chile).

\section{Fragmentos de identidade local no cinema de ficção rodado na região de Bío-Bío, Chile}

\section{Resumo}

Esta pesquisa tem por objetivo geral conhecer fragmentos identitários da região de Bío-Bío, no Chile, que estão presentes no cinema de ficção rodado nessa área entre os anos de 2010 e 2017. Em termos específicos, busca-se indagar sobre a contribuição do cinema na construção de identidade local, assim como hierarquizar os traços identitários detectados na amostra fílmica. A metodologia empregada identificou a produção cinematográfica da região para depois indagar sobre possíveis traços que de alguma maneira pudessem caracterizar a comunidade local no período indicado. Para isso, levou-se em consideração o conteúdo dos filmes analisados e foram realizadas uma entrevista grupal e entrevistas individuais com fontes especialistas e informantes-chave, respectivamente, cujas descobertas foram contrastadas com um estudo documental que oferece uma contextualização no âmbito local. Igualmente, utilizou-se teoria sobre identidade para dar apoio epistêmico ao desafio proposto nos objetivos. Finalmente, analisou-se a presença ou a ausência de traços identitários na amostra fílmica por meio da observação direta e da análise de personagens e ambientes: é notável, nesse sentido, o fato de que os traços identitários mais recorrentes no cinema analisado sejam catástrofes naturais, seguidas dos traços indígena e camponês. Por outro lado, determinou-se que a maioria dos filmes realmente apresentam muitos dos possíveis traços identificados e construídos coletivamente na área. Portanto, conclui-se que o cinema da região estudada contribui, no período analisado, à construção de uma identidade local por meio da inclusão de fragmentos identitários específicos que são explícitos nos filmes.

Palavras-chave: cinema; identidade; construção de realidade; traços identitários; significação social; cultura, localidade; Bío-Bío (Chile). 


\section{Introducción}

La noción de identidad desde la que aquí nos ubicamos apunta al medio social en que los individuos se definen a sí mismos en estrecha interacción simbólica con otras personas. Este es un proceso de construcción permanente en el que influyen atributos culturales, valóricos, afectivos y comunicativos (Berger y Luckmann, 1976). Por lo tanto, la 'identidad regional' (Giménez, 2005) se ha de entender aquí como aquella que distingue a las personas que habitan en un determinado territorio: lo que las define y con lo que se reconocen. Desde esa perspectiva, el cine tiene una relación estrecha con el concepto de identidad, pues permite que los espectadores comprendan e interpreten las escenas de una película, lo cual desencadena en ellos un reconocimiento propio, emociones y sentimientos.

El filme como forma artística ayuda a la reflexión y habla sobre el tiempo en que se vive. El cine ha sido innumerables veces la cámara que ha grabado la historia, mostrando diversas épocas y contextos (Villarroel, 2005). La película revela rasgos identitarios de los espectadores, lugares emblemáticos de la región, modismos, repasa la historia y es un medio que muestra la realidad social de un lugar (Gubern, 1969). Todos estos aspectos son relevantes para entender la importancia del cine como co-constructor de la identidad regional.

La historia, la identidad y la cinematografía ostentan una relación estrecha que se descubre cuando los espectadores se reconocen, comprenden e interpretan las escenas de las películas, hecho que provoca en ellos una emoción. A diferencia de la televisión, y al tratarse de un medio de ficción, el cine no se considera una fuente informativa; sin embargo, en periodos de crisis influye a menudo en la opinión de las personas (Montero y Rodríguez, 2005), con lo cual se constituye en medio de comunicación relevante para construir e interpretar la realidad social contemporánea.

Esta investigación parte del supuesto de que el cine regional producido en años recientes contribuye a la construcción de la identidad local de los habitantes de la región del Bío-Bío, Chile. Por lo tanto, las películas producidas en la zona son un medio que expresa y co-construye rasgos identitarios desde y con la comunidad. Como lo señala Rosenstone (1997), el cine se debe entender como un medio cultural, un vehículo para reconstruir la historia y analizar el pasado.

El filme construye realidad por medio de códigos y recursos audiovisuales. Se hace necesario, entonces, visualizar el cine como co-constructor de las creencias y valores de una comunidad siempre mutable, en la que cada narrador ajusta el método de creación a los rasgos y peculiaridades de su propósito, o bien a las particularidades de cada cultura. Por lo tanto, el material audiovisual estará al servicio de múltiples y diversas formas de subjetivación de la realidad, sueños y mitos, es decir, 
extensiones arquetípicas para una identificación cultural, expresadas en la figura de cada guionista/realizador (Fuente-Alba y Basulto, 2018).

Esta investigación entiende el cine como un medio valioso para la cultura, testimonio de la historia humana y depositario de posibles fragmentos identitarios que contribuyen de forma dinámica a la construcción de identidad en la región del BíoBío, según el caso de estudio que aquí nos convoca. Por lo tanto, el objetivo general de la investigación radicó en conocer fragmentos identitarios de la región estudiada, presentes en el cine de ficción rodado allí entre 2010 y 2017. De forma específica, se buscó indagar sobre la contribución del cine en la construcción de identidad local, y jerarquizar rasgos identitarios detectados en la muestra fílmica.

La estructura del presente artículo consta de cuatro etapas. En la primera se desarrolla una discusión teórica en torno a conceptos relevantes como cultura, identidad y significación social, para entender el posicionamiento que nos mueve como investigadores a relacionar el cine local con la construcción de identidad regional. Asimismo, se realiza un estudio documental a partir de los rasgos económicos, históricos y culturales que caracterizan a la región del Bío-Bío. En la segunda etapa se identifica la producción cinematográfica a través de la elaboración de un catastro de las películas filmadas en la región del Bío-Bío entre 2010 y 2017, para luego identificar y co-construir rasgos identitarios a través de un análisis que compara los datos del grupo focal realizado a fuentes expertas y entrevistas a informantes clave, con el estudio documental y teórico previo realizado por los suscritos investigadores.

En la tercera etapa, a su turno, se analiza la presencia o ausencia de los rasgos en cuestión en la muestra fílmica mediante la observación directa y el análisis de personajes y ambientes, sumado a los postulados de contenido aparente y contenido latente de cada película; y en la cuarta, el análisis de dichos datos permite realizar inferencias en torno a la contribución del cine regional en la construcción de identidad de la zona, así como en relación con los rasgos identitarios más y menos recurrentes en la muestra fílmica. Finalmente, se presentan conclusiones que llevan a reflexionar sobre los rasgos identitarios específicos que se construyen desde las películas, y sobre la manera en la que el cine contribuye en la co-construcción de una dinámica y provisoria identidad local contemporánea.

\section{Cultura e identidad como promotores de significación social}

Para visualizar lo que se puede comprender como identidad, primero parece necesario hacerse cargo de la noción de cultura. En este sentido, el antropólogo Clifford Geertz (1992) la define como "pautas de significación", pero cada vez menos definidas, es decir, más flexibles y cargadas de dinamismo social en una lucha de prevalencia de 
significaciones que buscan su espacio, adentrados en un siglo xxı cada día más complejo en términos de interacción social; y en el que el análisis del comportamiento humano se hace indisociable de visibilizar una realidad multidimensional a partir de la existencia de prácticas sociales que adquieren gran valor simbólico (Durand, 1971). Al mismo tiempo, es primordial insistir en una perspectiva en que la cultura no se debe entender como un repertorio homogéneo, estático e inmodificable de significados; por tanto, constituye una arquitectura nunca acabada (Baeza, 2000).

Ahora bien, se requiere volver sobre la relación que se establece entre cultura e identidad: ¿por qué será importante saber el tipo de personas que somos y cómo nos identificamos con algunos de nuestros propios parámetros? ¿Por qué la identidad constituye uno de los ejes centrales de los estudios culturales? (Hall, 1981; 1990; Hoggart, 1970). Quizás la respuesta está en la misma complejidad de la identidad, formada por una multiplicidad de elementos que hacen hincapié en el sujeto descentrado, en el "yo" constituido por identidades múltiples y cambiables (Barker, 2003) que dan forma a la plasticidad de la identidad.

Es decir, desde la perspectiva de Stuart Hall (1990), el sujeto asume diferentes identidades en distintos momentos. Dichas identidades no están unificadas en torno a un "yo" coherente: coexisten múltiples identidades contradictorias que se tensionan en distintas direcciones, de modo que nuestras identificaciones están sujetas a cambios de forma continua. Solo se entiende que sintamos tener una identidad unificada toda la vida porque construimos una historia reconfortante, o "narrativa del yo", sobre nosotros mismos. Pensar la identidad como un cúmulo totalmente unificado, completo, seguro y coherente es una fantasía. Por lo tanto, cabe hablar de identidades con un amplio dinamismo y en permanente estado de cambio.

De este modo, la identidad aparece definida a través de marcadores culturales que generan ciertas fronteras entre grupos sociales (Barth, 1976), e inclusive dentro de la persona o grupo de personas. La identidad parece estar relacionada con un proceso de identificación social en el que la cultura tiene mucho que decir. Entonces, la problemática radica en la forma en la que la identidad construye fronteras sociales a partir de múltiples y permanentes cambios políticos y culturales. Desde esta perspectiva, identidad y cultura son dos nociones complementarias en constante pugna por delimitar fronteras sociales a partir de rasgos socioculturales.

Al llevar esta conceptualización a un plano más operativo, y realizada una distinción preliminar, la identidad tendría que ver con el modo en que individuos y grupos se definen a sí mismos, al quererse relacionar o identificar con ciertas características (Tugendhat, 1996), y en diferenciación con respecto a otros. Así entonces, nos referimos a la identidad como un fenómeno ontológico y construido (Boisier, 2006, p. 76). 
¿Cuál será la importancia del cine en relación con procesos de construcción socioidentitaria? Fundamentalmente, dicha relevancia pasaría porque en la estructura de una obra está incorporada la narración de nuestros pasados y presentes; la comprensión histórica de nuestra realidad con sus prejuicios y bemoles. Por lo tanto, el cine local puede abrir nuevos horizontes en la configuración de mundos locales o en el anclaje de ciertos rasgos identitario-culturales, aspecto relevante que queremos poner en el tapete a través del presente artículo. "Las películas se constituyen en una estructura narrativa que contiene el verosímil fílmico que una sociedad se ha creado de sí misma en una época dada" (Morales y Maza, 2014, p. 162). Asimismo, el séptimo arte permite montar escenarios mentales presentes en la memoria, imágenes del espacio que nos permiten recrear de forma virtual la espacialidad que habitamos (Alvarado, 2018).

\section{Identidad y cultura regional en el cine de ficción del Bío-Bío}

Cuando se habla de identidad y cultura regionales resulta primordial mencionar que son todo aquello que distingue a quienes habitan en el territorio: lo que las define y con lo que se reconocen en la contemporaneidad. Estos y otros fenómenos forjan la identidad de un pueblo. Para la región del Bío-Bío, por ejemplo, resultan significativos distintos procesos identitarios de larga data que están determinados por una serie de factores, tales como el intercambio cultural entre las cosmovisiones occidental y mapuche (Azcona, 2016). También son factores las características sociohistóricas fundacionales de sus ciudades; los rasgos urbanos y geográficos de sus territorios; las catástrofes naturales permanentes en el tiempo; y la memoria social transmitida por generaciones (Casanueva, 1993; Halbwachs, 2004).

Las características geográficas, los elementos históricos y las particularidades urbanas manifiestan variadas expresiones en la región. Pese a que la zona ha sufrido las inclemencias de la naturaleza, que terminaron con buena parte del patrimonio arquitectónico de edificios magníficos, se puede reconocer una identidad que ha estado definida por dicho carácter urbano (Witker, 2001): ejemplo de ello es Concepción, en tanto capital de la región del Bío-Bío, con su carácter industrial, comercial, universitario y provisto de una fuerte cultura subterránea. Estos rasgos históricos que comparten los habitantes de la región estudiada son características que se apropian de ciertos repertorios del entorno social, en un grupo o en la sociedad en su conjunto. Ello resulta más claro todavía si se considera que la primera función de la identidad es marcar fronteras entre los habitantes de la región y "los "otros", y no se ve de qué otra manera se pueden diferenciar de los demás salvo a través de una constelación de rasgos culturales distintivos (Giménez, 2005), según lo hemos definido.

En la misma línea de lo que se viene planteando, es posible constatar algunos rasgos que configuran identidad en la zona. Por ejemplo, existen elementos potentes 
que tienen que ver con una historia precolombina, marcada por la cultura mapuche, la cual perdura hasta nuestros días, pero como minoría étnica. Al mismo tiempo, tiene que ver con una zona donde históricamente se ha resistido mucho: se opuso resistencia al colonialismo español, momento en el que el río Bío-Bío sirvió de frontera; luego, en Concepción, se firmó la independencia de Chile, y mucho más adelante se luchó con fervor contra la dictadura militar de Pinochet, pues en esta localidad surgieron movimientos políticos que se movilizaron en franca resistencia al neocolonialismo capitalista (Arboleya, 2007) —entendido como base de un diseño institucional neoliberal impuesto para Chile (Báez, 2017)—, pese a que finalmente se sucumbió en la lucha y se implementó estructuralmente dicho diseño (Zúñiga, 2011).

En la actualidad, la región del Bío-Bío, y Concepción en especial, parecen tener una memoria social (Halbwachs, 2004) débil en torno a la génesis de movimientos socioculturales y políticos de relevancia, así como una falta de consciencia respecto al valor de lo patrimonial (Basulto, 2014), hecho que dificulta procesos de identificación cultural crecientes y sostenidos dentro de una diversidad dinámica y progresiva de la sociedad. Pero, tal como se desprende de Halbwachs, la memoria social contribuye a una tarea resignificadora, relativa en este caso a las identidades culturales. Por tanto, hacemos referencia a un proceso de co-construcción social - vale decir una construcción subjetiva social, una estabilización permanente y socialmente compartida de lo significado — que en la actualidad ha entrado en crisis, si pensamos desde referentes amparados en una tradición identitario-cultural de larga data.

Desde esta perspectiva, el cine de ficción parece fundamental al pensar en la construcción identitario-cultural de la región del Bío-Bío, eje central que convoca el presente artículo. El cine de ficción tiene la capacidad de proyectar la realidad de su tiempo y demostrar a los espectadores parte de su historia. Según Raack (1983), las imágenes son más apropiadas para explicar la historia que las palabras: según él, los libros son incapaces de mostrar el complejo y multidimensional mundo de los seres humanos. Solo las películas — capaces de incorporar imágenes y sonidos, de acelerar y reducir el tiempo- se pueden aproximar a dicho mundo. El cine ofrece una reconstrucción del pasado y una explicación del presente (Rosenstone, 1997). Es incluso más conmovedor, como dice Bazin, ya que multiplica la calidad del momento original por el contraste de su repetición. Le confiere una solemnidad suplementaria. El cine ha dado a la muerte de "Manolete" una eternidad material: En la pantalla, el torero muere todas las tardes (Bazin, 1966).

Por lo tanto, no es extraño que el cine de la región del Bío-Bío también tenga influencia a nivel local y contenga algunos rasgos distintivos de la zona. Esto adquiere relevancia cuando se le entiende como aquel instrumento narrativo que permite traer a la vida el acontecimiento otra vez, manteniendo vivo su recuerdo en el espectador. 
El cine no solo construye una percepción del mundo, sino que, en un sentido más radical, produce realidad (Lipovetsky y Serroy, 2009); tiene una vocación ontológica de producir y reproducir lo real, lo que se puede traducir en representaciones dotadas de la misma ambigüedad que la realidad (Bazin, 1966). Allí apuntan nuestros esfuerzos investigativos: conocer si nuestro cine, el cine regional, contiene fragmentos identitarios que co-construyen identidad con los habitantes del Bío-Bío, o se identifican con dichos rasgos.

\section{Cinematografía nacional}

El cine de ficción tiene la capacidad de proyectar la realidad de su tiempo y demostrar a los espectadores parte de su historia. En Chile corresponde remontarse a 1910 para conocer los inicios de la cinematografía nacional: ese año se estrenó Manuel Rodríguez, un cortometraje mudo y en blanco y negro dirigido por el actor y director Adolfo Urzúa Rosas. Luego, en 1934, Jorge Délano realizó Norte y Sur, la primera película sonora del país. En 1960, el campo cinematográfico nacional enfrentó sus años de mayor producción con el surgimiento del "nuevo cine latinoamericano", con lo cual surgieron realizadores como Raúl Ruiz, Miguel Littin, Helvio Soto, Patricio Guzmán, Aldo Francia y Patricia Kaulen. Aquella fue la década del pleno funcionamiento de Chile Films, empresa estatal que tenía por objetivo impulsar el cine nacional mediante la producción de películas no solo para el público local, sino también para el resto de América Latina (Villarroel, 2012).

El cine de inicio de la década de 1970 integró el proceso político, con las películas Ya no basta con rezar de Aldo Francia (1972), o Voto más fusil de Helvio Soto (1971). Durante la dictadura militar (1973-1989), el cine nacional se silenció: el desmantelamiento incluyó instituciones del Estado, los departamentos de cine y arte de varias universidades. Esto se acompañó por el desmantelamiento de Chile Films y la derogación de la Ley de protección del Cine, vigente desde 1967. En la década de 1980, la censura y la autocensura fueron protagonistas del cine; resultó una época compleja para los realizadores. Algunos hicieron cine de diversos formatos a pesar de las circunstancias hostiles, entre los que se encuentran Juan Carlos Bustamante, Patricio Bustamante, Silvio Caiozzi, Gonzalo Justiniano y Cristián Sánchez. La publicidad, entonces, fue su refugio, y se constituyó en escuela de muchos directores y técnicos de la década de 1990 (Varas, 2006).

Con el regreso a la democracia en 1990, el cine experimentó una secuencia de películas que retrataban el golpe de Estado y el desequilibrio político de aquella época. El cine chileno de inicios del siglo xxı, a su turno, fue un medio que buscó en una primera etapa una referencia al pasado inmediato, en tanto aludía de modo metafórico a los tiempos de la dictadura, al autoritarismo, a la contención y a la presencia de un país diverso que transita entre lo popular, la crítica al modelo económico, 
la memoria y el olvido, la traición y la modernidad junto al desarrollo y la pobreza (Villarroel, 2012). Con la promulgación de la Ley de Fomento Audiovisual (Ley n. ${ }^{\circ}$ 19.981) en 2004, la creación del Consejo de las Artes y la Industria Audiovisual (CAIA) y del Fondo de Fomento Audiovisual, se hizo posible el desarrollo de una producción fílmica que años después alcanzaría números históricos. Este incremento en la producción permitió una diversificación temática, narrativa, estética y estilística que ha logrado una importante circulación y reconocimiento en el circuito global de festivales de cine y premios internacionales (Pinto, González y Munjin, 2018). En la actualidad, la industria cinematográfica ha decantado en temas propios de la contingencia social: las diferencias de clases, la soledad, la identidad de género y la voz de las minorías son retratadas en el cine chileno con grandes resultados, como el Oscar a la mejor película extranjera en marzo del 2018 con el filme Una mujer fantástica de Sebastián Lelio.

Al constatar la evolución del cine chileno en poco más de cien años podemos darnos cuenta de que el contexto social de diferentes épocas es plasmado — quiérase o no- en la construcción del material fílmico en un periodo determinado. Dicha cuestión también se puede extrapolar al cine regional en todas sus dimensiones; y específicamente para el caso de este estudio, a partir de la presencia y construcción de fragmentos identitarios locales.

\section{Metodología}

Esta investigación es de carácter mixta, esto es, cualitativa y cuantitativa (Ibáñez, 1985; Hernández-Sampieri y Mendoza, 2008): por un lado, se levantó y analizó información discursiva a través de entrevistas individuales y grupales; y por otro, se consideraron datos cuantitativos extraídos del análisis de la muestra fílmica (tabla 1).

Tabla 1. Sistematización de las unidades de análisis

\begin{tabular}{|c|c|}
\hline $\begin{array}{l}\text { Unidad de } \\
\text { análisis }\end{array}$ & Relación con rasgo identitario \\
\hline Personaje & $\begin{array}{l}\text { Para determinar la relación con el rasgo identitario se distingue la relación entre el } \\
\text { personaje principal y su objetivo en la película. }\end{array}$ \\
\hline Ambiente & $\begin{array}{l}\text { Para determinar la relación con el rasgo identitario se distingue el entorno en el que } \\
\text { se mueve el personaje y dónde está situado, es decir, lugar geográfico o coordenadas } \\
\text { espaciotemporales. }\end{array}$ \\
\hline $\begin{array}{l}\text { Contenido } \\
\text { aparente }\end{array}$ & $\begin{array}{l}\text { La relación con el rasgo identitario surge de una visión descriptiva y no analítica del } \\
\text { filme, que puede ser realizar cualquier espectador con base en el argumento central. }\end{array}$ \\
\hline $\begin{array}{l}\text { Contenido } \\
\text { latente }\end{array}$ & $\begin{array}{l}\text { Para determinar la relación con el rasgo identitario se analiza y critica el filme de acuer- } \\
\text { do con una interpretación que pone en contacto los elementos del lenguaje cinema- } \\
\text { tográfico y el tiempo representado (universo sociohistórico del filme, de acuerdo con } \\
\text { el cual se entienden las acciones de los personajes) y con el tiempo de representación } \\
\text { (situación social, ideológica y política en la que se produce el filme). }\end{array}$ \\
\hline
\end{tabular}

Fuente: elaboración propia. 
En congruencia con los objetivos de la investigación, este artículo busca analizar el cine regional como constructor de identidad local durante el periodo 2010-2017. Para ello se analizaron largometrajes (películas de duración superior a 60 minutos) de ficción rodados en la zona en el periodo señalado, es decir, la totalidad de las cintas que utilizaron locaciones en la región del Bío-Bío, y se profundizó en su relación con los rasgos identitarios reconocibles de la región a través de la identificación de aspectos de la zona y su historia, a partir del estudio documental (Baena, 1988) previamente expuesto. Asimismo, para la identificación y construcción de rasgos identitarios locales se tuvo en cuenta el contenido de las películas analizadas, y se realizaron una entrevista grupal y entrevistas individuales con fuentes expertas (Giddens, 1999) e informantes claves (Punch, 2005), respectivamente; esto se contrasta con el estudio documental, lo que hizo posible disponer de una contextualización local, y además se utilizó la teoría sobre identidad para dar sustento epistémico al desafío planteado en los objetivos.

De modo más detallado, el estudio constó de un diseño metodológico conformado por cuatro etapas, complementadas por la discusión teórica con respecto a la identidad de la zona, lo que permitió elaborar la pauta de entrevistas del grupo focal. La primera etapa correspondió a un catastro de los filmes rodados en la región del Bío-Bío durante el periodo analizado. Lo anterior se basó en datos del Consejo de la Cultura y las Artes, contrastados con los archivos de la Comisión Fílmica del Bío-Bío e información otorgada por productoras y universidades de la zona. Como resultado de este catastro se identificaron once filmes rodados en la región durante el período estudiado (tabla 2). Como parte de esta primera etapa se realizó un estudio documental relacionado con la caracterización histórica, económica y cultural de la región del Bío-Bío, así como una fundamentación teórica sobre identidad, ya mencionada.

Tabla 2. Películas rodadas en la región del Bío-Bío entre 2010-2017

\begin{tabular}{|c|c|c|}
\hline Película & Director & Sinopsis \\
\hline 03:34 Terremoto en Chile (2011) & Juan Pablo Ternecier & $\begin{array}{l}\text { La película se centra en la historia paralela de } \\
\text { tres familias que vivieron el terremoto del } 27 \text { de } \\
\text { febrero del } 2010 \text { en una localidad costera al sur } \\
\text { de Chile. }\end{array}$ \\
\hline Sentados frente al fuego (2011) & $\begin{array}{l}\text { Alejandro Fernández } \\
\text { Almendras }\end{array}$ & $\begin{array}{l}\text { Daniel y Alejandra, una pareja de edades cer- } \\
\text { canas a los } 40 \text { años, dejan la ciudad y buscan } \\
\text { suerte en el campo. Alejandra sufre de una en- } \\
\text { fermedad que consume sus sueños y pone a } \\
\text { prueba el amor. }\end{array}$ \\
\hline $\begin{array}{l}\text { En las afueras de la ciudad } \\
\text { (2011) }\end{array}$ & $\begin{array}{l}\text { Juan Pablo } \\
\text { Valladares }\end{array}$ & $\begin{array}{l}\text { La película, inspirada en un hecho real, cuenta } \\
\text { la historia de Ana y Anny, dos hermanas que } \\
\text { crecieron aisladas y rodeadas del tráfico de dro- } \\
\text { gas y la obsesión incestuosa de su padre. }\end{array}$ \\
\hline
\end{tabular}




\begin{tabular}{cll}
\hline Película & \multicolumn{1}{c}{ Director } & \multicolumn{1}{c}{ Sinopsis } \\
\hline & & $\begin{array}{l}\text { Jorge, un padre de familia, sufre un asalto. Su } \\
\text { hijo decide recuperar lo robado y es baleado } \\
\text { Matar a un hombre (2014) }\end{array}$ \\
& $\begin{array}{l}\text { Alejandro Fernández delincuente, quién tras salir de la cárcel } \\
\text { Almendras }\end{array}$ & $\begin{array}{l}\text { intimida a la familia. Jorge decide hacer justicia } \\
\text { por sí mismo. }\end{array}$ \\
\hline
\end{tabular}

Dos hermanas de origen mapuche son contratadas por una empresa eléctrica para realizar una

Gritos del bosque (2014) Jorge Olguín excursión por un bosque en Arauco. Sucesos extraños ocurren durante la visita del grupo, ya que en el bosque habitan espíritus guerreros mapuches.

Tras escapar de ser asesinado por uniformados

Huesos rotos (2014) Ricardo Mahnke golpistas (Golpe de Estado de 1973), Manuel González regresa a su pueblo natal, donde los recuerdos de la represión vuelven a la vida.

\begin{tabular}{ll}
\hline Konun Wenu (2014) & Un niño pehuenche vive con sus abuelos en la \\
& cordillera, ellos le narran leyendas indígenas. \\
& Un día, Akun se pierde en el bosque y decide ir \\
& en busca del espíritu de Konün Wenu, o puerta \\
& al cielo, a ver a su madre que murió hace algu- \\
& nos años.
\end{tabular}

Joe, un ciclista profesional, decide volver al deporte en Chile. Durante una práctica con su noDownhill (2015) Patricio Valladares via se topan con un hombre que está muriendo por un misterioso virus. Se convierten entonces el objetivo de un asesino que haría cualquier cosa por mantener su secreto en las montañas.

\begin{tabular}{ll}
\hline Johnny cien pesos 2 (2016) & $\begin{array}{l}\text { Gustavo Grief } \\
\text { Marino }\end{array}$
\end{tabular} \begin{tabular}{l}
$\begin{array}{l}\text { Después de veinte años en prisión, Juan, alias } \\
\text { Johnny } 100 \text { Pesos, sale en libertad y se enfrenta } \\
\text { a un país completamente desconocido y hostil. }\end{array}$ \\
\hline
\end{tabular}

Una acomodada familia, sumergida en la rutina

Nublado, cubierto y lluvia (2016) Fernando Solís individualista, se enfrenta a situaciones que hacen replantear el rumbo de sus vidas a sus miembros, en una ciudad que perdió la estabilidad tras un gran terremoto.

La falta de noticias en un pequeño pueblo campesino lleva a un periodista fracasado a inventarlas para no perder su trabajo. Al convertirse en el reportero más popular de la región, deberá decidir entre seguir mintiendo o contar la verdad y perderlo todo. 
Durante la segunda etapa se buscó levantar información sobre los rasgos identitarios de la región del Bío-Bío. Para ello se implementó un grupo focal (HernándezSampieri, Fernández y Baptista, 2006) con profesionales y expertos locales en temáticas referidas a la identidad y cultura, además de entrevistas estructuradas con informantes clave que complementaron la información obtenida a partir del grupo focal. El grupo focal estuvo conformado por siete personas, todas de la región del Bío-Bío, entre las que se destacan tres historiadores, un periodista experto en interculturalidad, un sociólogo académico de la Universidad de Concepción, un artista visual y un director de cine; las entrevistas cualitativas semiestructuradas (Valles, 1997), se realizaron a una académica experta en geografía humana y a un sociólogo. Por lo tanto, todas las muestras de esta investigación poseen un carácter intencionado (Valles, 1997).

Con todo lo anterior fue posible identificar y señalar ciertos rasgos identitarios que caracterizan a la región (véase el ítem de resultados de la tabla 3). Se hace necesario acotar que dichos rasgos solo surgen a partir de un análisis de todas las fuentes, en lugar de considerar verdad última alguna instancia de recopilación de información: ni la opinión de los expertos, ni el estudio documental, ni la revisión teórica previa realizada por los investigadores constituyen verdad puesto que consideramos, en el sentido de Bachelard (1928), que pensar en alcanzar la verdad no puede más que inducir al error permanente, en lugar de llevar a un conocimiento certero. En cualquier caso, dicho trabajo permite relacionar la caracterización histórica, económica y cultural de la región del Bío-Bío con la episteme construida para este artículo, a partir de todos los elementos analizados. Por lo tanto, no aludimos a certezas sino a representaciones de sentido que nos permiten significar y construir posibles rasgos identitarios a nivel local, entendiendo que la realidad social es construida permanentemente al igual que la identidad (Berger y Luckmann, 1976).

Tabla 3. Rasgos identitarios de la región del Bío-Bío

\begin{tabular}{ll}
\hline \multicolumn{1}{c}{ Rasgo } & \multicolumn{1}{c}{ Definición } \\
\hline \multirow{2}{*}{ Enfrentamiento } & $\begin{array}{l}\text { Se relaciona directamente con la resistencia y la lucha o reacción organizada } \\
\text { contra la fuerza pública y autoridades por parte de pueblos indígenas y vice- } \\
\text { versa. Así como también, la lucha contra dictaduras militares y violencia de } \\
\text { Estado en general. }\end{array}$ \\
\hline Diferenciación & $\begin{array}{l}\text { Corresponde a la contraposición a otras regiones y la necesidad de diferenci- } \\
\text { arse de ellas, especialmente a la identidad centralista capitalina. }\end{array}$ \\
\hline \multirow{2}{*}{ Identidad histórica } & $\begin{array}{l}\text { Corresponde al conjunto de lazos sociohistóricos de guerra y conquista. Hace } \\
\text { refencia a la historia de la región, pasado colonial, expansión y conectividad } \\
\text { Eje económico las provincias que componen la región del Bío-Bío. }\end{array}$ \\
\hline & $\begin{array}{l}\text { Corresponde a las actividades económicas que explotan los recursos naturales } \\
\text { de la región como son las actividades pesquera, forestal, ganadera y minera. }\end{array}$ \\
\hline
\end{tabular}




\begin{tabular}{ll}
\hline \multicolumn{1}{c}{ Rasgo } & \\
\hline Identidad indígena & $\begin{array}{l}\text { Corresponde a la relación que tiene la región del Bío-Bío con los pueblos origi- } \\
\text { narios. Este rasgo se vincula con mapuches y pehuenches, pueblos que habitan } \\
\text { y se relacionan con la montaña, lagos y recolección. }\end{array}$ \\
\hline $\begin{array}{l}\text { Identidad } \\
\text { occidental }\end{array}$ & $\begin{array}{l}\text { Corresponde a la vinculación con Estados Unidos y Europa, a manera de imit- } \\
\text { ación del paradigma del gran estilo de vida americano. }\end{array}$ \\
\hline Campesino & $\begin{array}{l}\text { Corresponde a la conformación de la hacienda, el patrón, el peón, el inquilinaje } \\
\text { y todas las figuras del campo tradicional chileno; la agricultura, como actividad }\end{array}$ \\
\hline Capital cultural & tación de pobreza, expresada en la marginalidad del mundo rural. \\
\hline Catástrofes & Expresiones culturales como el arte, la música y la literatura que se aprecian en \\
naturales & $\begin{array}{l}\text { Rasgos que identifican a la región como una zona de tragedias naturales, que se } \\
\text { han desarrollado a partir de la destrucción y la reconstrucción urbana y moral } \\
\text { de la población en muchos momentos de la historia local. }\end{array}$ \\
\hline Carácter & $\begin{array}{l}\text { Corresponde a la vasta cantidad de centros de educación superior que posi- } \\
\text { cionan a la ciudad de Concepción como un territorio académico-universitario. }\end{array}$ \\
\hline
\end{tabular}

Fuente: elaboración propia.

Hecho lo anterior, la tercera etapa tuvo como centro el análisis de la presencia relativa de los rasgos mencionados en las películas rodadas en la región y periodo estudiados mediante dos técnicas: de un lado, la observación directa de cada película; y de otro, una fusión entre la metodología de análisis de personaje principal y ambiente propuesta por Federico Di Chio y Francesco Cassetti (2002) y los postulados de contenido aparente y contenido latente propuestos por Gloria Camarero (2002). Dicho complemento metodológico se explica a continuación.

La cuarta y última etapa correspondió al análisis de contenido (Díaz, 1992) de las películas: este permite realizar inferencias en torno a la contribución del cine regional en la construcción de identidad de la zona y a los rasgos identitarios más y menos recurrentes en la muestra fílmica. Para esto último se realizó un análisis inferencial descriptivo (Fernández, Cordero y Córdoba, 2002) a partir de los gráficos presentados en los resultados del estudio.

\section{Resultados}

El catastro realizado entregó información importante respecto a las cintas. Once películas se rodaron ${ }^{1}$ en la región del Bío-Bío entre 2010 y 2017 (1,37 filmes por año, en promedio). De ellas, 72 \% surgió de producciones nacionales, mientras que el $28 \%$ restante correspondió a coproducciones internacionales. La división del rodaje

Es preciso aclarar que las películas rodadas en los años señalados no necesariamente fueron estrenadas en dicho periodo. El rodaje tiene que ver con la grabación de la película, y el estreno con la divulgación al público espectador. 
por zonas geográficas arroja que el 45 \% de las películas se rodó en la Provincia de Concepción, y un 36 \% de ellas en la Provincia de Ñuble², mientras que las provincias de Arauco y Bío-Bío registraron cada una un 9 \% de rodajes (tabla 2).

A partir de un análisis documental de la caracterización histórica, económica y cultural de la región del Bío-Bío, sumado a un análisis de las películas señaladas (tabla 2) y producto de la comparación de datos extraídos del grupo focal y de las entrevistas a informantes clave, se distinguieron diez rasgos identitarios de dicha zona (tabla 3), que se contrastaron con las unidades de análisis descritas anteriormente.

Una vez identificados y construidos dichos rasgos identitarios, se determinó que 64 \% de las películas de ficción rodadas en el periodo y región estudiados 7 de 11 películas) presenta uno o más rasgos identitarios en algunas de sus unidades de análisis, esto es, personaje, ambiente, contenido aparente o contenido latente (figura 1). Este punto es importante, pues las realidades ficticias presentadas en los filmes contribuyen, en su gran mayoría, a construir rasgos que distinguen identitariamente a la zona.

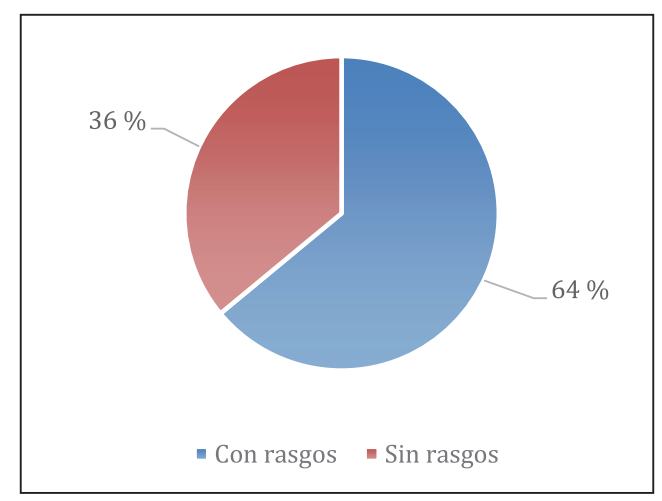

Figura 1. Rasgos identitarios en filmes, 2010-2017

Fuente: elaboración propia.

El rasgo identitario con más presencia en las películas analizadas (figura 2) correspondió a catástrofes naturales, con un $28 \%$ de presencia en las realizaciones (3 de 11 películas), y recurrente en largometrajes como 03:34 Terremoto en Chile, Sentados frente al fuego y Nublado, cubierto y lluvia. Esto se explica por cuanto la región del Bío-Bío se caracteriza por ser una zona de tragedias y catástrofes naturales en el ámbito nacional. De hecho, la más recordada por el colectivo regional es el terremoto ocurrido tiembre del 2018 entró en vigencia el decreto que creó la región de Ñuble. 
el 27 de febrero del 2010, también conocido como "27-F" (según el último escalafón de terremotos realizado por el Servicio Geológico de los Estados Unidos, es el tercer sismo más grande en la historia de Chile, y el octavo más fuerte a nivel mundial). Al mismo tiempo, es importante tener presente que Chile es uno de los países más sísmicos del mundo, y la zona en cuestión ha sido una de las más afectadas por este tipo de catástrofes en la historia del país.

Otro rasgo importante es la "identidad indígena", con un $18 \%$ de presencia en las películas. Este rasgo se evidenció en largometrajes como Gritos del bosque y Konun Wenu: en ellos es posible apreciar la tradición que vincula a la región del Bío-Bío con los pueblos originarios, precisamente con los mapuches y pehuenches, que han habitado la cuenca superior del río Bío-Bío (Yáñez y Molina, 2011). Estos pueblos están relacionados con la montaña y la recolección, y en las películas se puede ver el vínculo de dichas etnias con la tierra y la naturaleza como un factor fundamental para su desarrollo. Este porcentaje (20 \%) también responde a la frontera natural e histórica que conforma la región del Bío-Bío en el mal llamado "conflicto mapuche", así como a la contingencia que pone a la zona en el centro de la crisis entre el Estado de Chile y el pueblo mapuche.

En similar porcentaje (18 \%) también se destaca el rasgo identitario "campesino", por medio del cual se identifica cinematográficamente a la importante población que desempeña labores agrícolas y vive en pueblos y comunas aledañas a las capitales provinciales. Esto último a pesar de que la región del Bío-Bío no es una de las grandes productoras agrícolas del país, puesto que sus zonas de cultivos han sido reemplazadas de forma sistemática por plantaciones forestales de carácter industrial.

Los rasgos "enfrentamiento" e "identidad histórica" también se presentan en la película Gritos del bosque. En este largometraje se relatan la guerra de Arauco y las consecuencias para el pueblo mapuche, además de la rivalidad entre indígenas y españoles. Dichos rasgos se presentan solo en un largometraje, y su inclusión simboliza la conformación histórica y geográfica de la región.

El rasgo "campesino", recurrente en largometrajes como Sentados frente al fuego y Mentirita Blanca, se evidenció con la incorporación de la vida en el campo: se muestran figuras tradicionales como el "peón", el "inquilino" o el "patrón", y todas se siguen manteniendo en el tiempo. Estas características se pueden apreciar en las películas, con lo que se evidencia el campo chileno no solo como paisaje, sino como escenario en el que se dan relaciones humanas particulares y únicas dentro de la sociedad chilena. El campo es el lugar del mestizaje ancestral y del choque, convivencia y hasta complicidad entre los extremos de la gama social que siguen los matices de la sangre india: el hacendado y el inquilino (Mizón, 2001). 


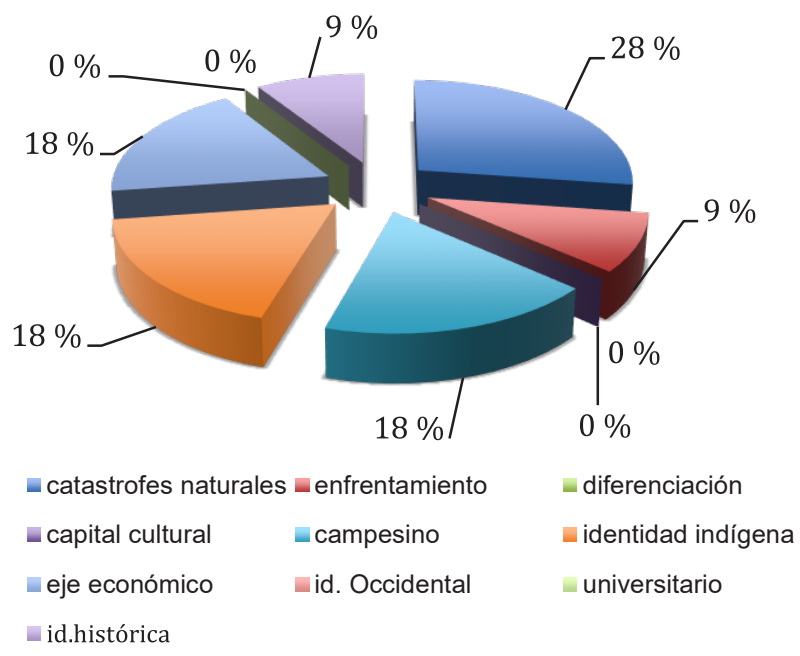

Figura 2. Rasgos con más presencia Fuente: elaboración propia.

El rasgo "eje económico", a su turno, estuvo presente en la película Matar a un hombre. Este filme muestra las labores de un trabajador forestal, actividad económica que explota los recursos naturales de la región. En el largometraje se aprecia y exponen labores directas de roce, plantación, poda, raleo, tala, cuidado y explotación de bosques, actividades propias de la actividad forestal, una de las principales de la región del Bío-Bío y que le permite diferenciarse de otras zonas del país.

Finalmente, los rasgos "capital cultural", "cultura occidental" y "diferenciación" no se presentan en ningún largometraje rodado en la región del Bío-Bío durante el periodo estudiado. Esto se puede explicar por cuanto el director utiliza la región solo como locación, pero sin ánimo alguno de contribuir a la identificación de rasgos culturales locales.

Al realizar un análisis de cada filme seleccionado, queda claro que algunos de ellos concentran mayor presencia de rasgos que otros. Las tres películas que concentran mayor cantidad de rasgos identitarios son 03:34, terremoto en Chile, Konun Wenu y Mentirita Blanca. En el caso de la primera película, el rasgo "catástrofes naturales" es transversal a todas las unidades de análisis: por un lado, se configura en el drama situacional de los "personajes" principales, pues el terremoto es el hecho trágico que hila el acontecer de las tres historias que conforman el filme; y por otro, se ve en el "ambiente", en la ambientación física o locación que parece ser un balneario en ruinas, y en una ambientación temporal que sitúa al filme en la madrugada, antes y después de la catástrofe ocurrida el 27 de febrero del 2010. En cuanto al "contenido aparente", 
las tres historias de la película se entrelazan en el conflicto central que inicia con el movimiento telúrico y las diferentes situaciones por las que atraviesan los personajes, en tanto que el hilo conductor del largometraje corresponde a un terremoto que provoca muertes y destrucción en una región del sur de Chile. Respecto al "contenido latente", el terremoto hace surgir lo peor y lo mejor del ser humano: De un lado, los saqueos, robos a supermercados y casas, la equivocación y falta de liderazgo de las autoridades, y la ausencia de preparación de Chile para ese tipo de situaciones, aun cuando han sido una constante en el transcurso de la historia de la zona y de gran parte del país; y de otro, se potencian aquellos valores de solidaridad del pueblo chileno con el más débil o más afectado.

Konun Wenu es otro de los filmes que presenta clara presencia de rasgos identitarios, especialmente "identidad indígena". Ambientada en la comuna cordillerana de Alto Bío-Bío, presenta a un niño pehuenche que tras la muerte de su madre decide acompañar a su abuelo a recoger los animales de la veranada. La identidad indígena está presente en todas las unidades de análisis, partiendo por el "personaje principal", un niño pehuenche que vive en casa de sus abuelos en el corazón del Alto Bío-Bío y rodeado de una naturaleza exuberante que brinda el marco ideal para el desarrollo del filme. Los ritos pehuenches que glorifican la naturaleza caracterizan "el ambiente" de la película, mientras que "el contenido aparente" se desarrolla a través de las comunidades indígenas, la casa de los abuelos, las araucarias, el piñón y los diferentes ritos del mundo pehuenche en su relación con la naturaleza. La identidad indígena en el "contenido latente" se marca con la presencia de espíritus ancestrales que vienen a sanar las heridas y a aceptar la muerte como un paso más hacia un mundo indígena mejor, en el que la sencillez y la importancia de los valores es idealizada por los abuelos pehuenches que invitan a ser correcto y honesto, respetando a todos los seres que habitan este mundo.

En Mentirita Blanca predomina el rasgo "campesino". La película muestra el quehacer de un equipo de periodistas de un diario local en una comuna rural de la región del Bío-Bío. Rodada en la comuna de San Carlos (provincia de Ñuble), su "personaje" principal es un periodista que regresa a trabajar al pueblo que lo vio nacer, mientras que su coprotagonista es un campesino que aprendió a realizar fotografías de forma empírica. El "ambiente" es el campo chileno, que también se retrata en el funcionamiento del diario El Esfuerzo con un jefe apatronado, en el que el periodista y el reportero gráfico no son más que peones del dueño del medio. El "contenido aparente" es claramente el contexto campesino y la labor de los medios en una zona agrícola con escasez. El "contenido latente" se caracteriza por la influencia que ejercen los medios de comunicación en personas menos informadas, así como en la inocencia del campesino chileno ante la presencia de consorcios con grandes capitales que, finalmente, se aprovechan de las personas con menos educación. 


\section{Conclusiones}

Al construir sus identidades, los individuos comparten ciertas afiliaciones o características grupales que contribuyen a especificar su sentido de identidad (Larraín, 2001). Estos rasgos que comparten los habitantes de la región consisten en la apropiación distintiva de ciertos repertorios que se encuentran en el entorno social, en un grupo o en la sociedad. Con esto se marca una frontera entre los habitantes de la región y otras localidades del país, que se diferencian a través de una serie de características identitarias culturales (Giménez, 2005). El cine como medio de comunicación que puede mediatizar (Martín-Barbero, 1998) formas de realidad social construida (Berger y Luckmann, 1976), plantea la posibilidad de entender la dinámica social desde la lógica de una comunidad imaginada en el sentido de Anderson (2007).

Desde esta perspectiva, el cine y su lenguaje (Bazin, 1966) pueden construir y reconstruir identidad y difundirla. Así entonces, el cine se puede entender como patrimonio cultural de una localidad, pues tiene la virtud de mostrar a la comunidad parte de su propia historia. Será entonces rol de los productores, realizadores e investigadores, como en este caso, velar para que el cine siga produciendo y reproduciendo, custodiando y — por qué no- cuestionando los fragmentos identitarios de las cada vez más diversas, cambiantes, dinámicas y complejas comunidades sociales (García Canclini, 2001; Kymlicka, 2007; 2010).

El cine, entonces, "amplifica el imaginario, porque lo instala en el dominio colectivo, en las diferentes audiencias a las que está dirigido" (Gallardo, 2008, p. 317). En este sentido, a la luz de los resultados de esta investigación, podemos señalar que el cine regional analizado posee una relación directa con gran parte de los rasgos identitarios identificados y co-construidos en el artículo. Esto se hace más evidente en la presencia de dichos rasgos, pero también a través del reconocimiento de lo dinámico y temporal de la identidad (periodo de tiempo analizado), lo que hace posible visibilizar distintas significaciones sociales a partir de los filmes rodados en la región del Bío-Bío.

Por lo tanto, a partir del cine se puede construir un registro audiovisual que se expresa desde el lugar en donde se graba y muchas veces constituye la manifestación del discurso de la gente que habita el territorio. Ante esa afirmación, quienes aquí investigan creen que es fundamental hacer dos distinciones, primero entre el cine que ocupa "locaciones de la región" para filmar y el cine que se filma en la zona construyendo identidad regional, pues claramente son cuestiones distintas con objetivos diferentes. Segundo, una cosa es reconstituir una época, es decir, crear una atmósfera que la evoque, y otra reconstruir un hecho, en el que se recrea de manera supuestamente fidedigna lo que ocurrió en un tiempo y un lugar determinados (Lozano, 2018).

En esta investigación es posible hacer ambas distinciones, pues más de la mitad de las películas no solo ocupan a la región como un escenario natural, sino que 
construyen identidad a través de algunos rasgos identitarios específicos que se han identificado y co-construido según la metodología descrita para este artículo. Para las películas que reconstruyen hechos específicos, en el caso de los filmes analizados, catástrofes, la intención de los directores es reconstruir una atmósfera inspirada en los propios recuerdos de los espectadores, pues los directores son conscientes de que la verdadera reconstrucción se da en la mente de las personas, más aún en aquellas que vivieron la experiencia directamente, lo cual en el tiempo puede constituir memoria social en el sentido de Halbwachs. Es decir, se produce un ejercicio de resignificación social al que están claramente invitados todos los individuos que contemplan el filme y que finalmente, en conjunto, contribuyen a una tentativa colectiva de significados que buscan una explicación generalizada. De este modo, parece plausible la construcción de unos "marcos sociales de la memoria" Halbwachs (2004) que sin duda reconfiguran identidades culturales en la localidad trabajada.

En este sentido, desde la teoría de identidad y cultura (Hall, 1981, 1990; Geertz, 1992; García Canclini, 2001; Anderson, 2007; Larraín, 2001; Barker, 2003; Kymlicka, 2010), que hemos trabajado para esta investigación, se hace bastante nítida la distinción que aquí ya podemos concluir: el cine no propone imagen identitaria, más bien co-construye identidad en una localidad cuando se produce una autoidentificación con ciertas características específicas y a partir del fortalecimiento de una estrecha relación simbólica (Durand, 1971) con lo que identificamos como propio (Tugendhat, 1996). Esta cuestión nos parece que se produce en buena medida en los filmes aquí ya analizados, en una re-producción y re-construcción permanente de la realidad social (Berger y Luckmann, 1976), puesto que el cine no solo construye una percepción del mundo, sino que, en un sentido más profundo, produce realidad (Lipovetsky y Serroy, 2009) y es aquí a donde se encuentran dirigidos nuestros esfuerzos investigativos, desde una perspectiva identitario-cultural regional.

Por lo tanto, lo anterior nos hace mucho sentido si ahora nos centramos en lo que ya hemos analizado de las películas estudiadas. Entonces, podemos señalar con propiedad que dichos filmes sí hacen eco y co-construyen muchos de los rasgos identitarios de la zona identificados y construidos en este artículo. Los resultados de esta investigación plantean que el 64 \% de las películas rodadas en el territorio regional construyen identidad local al exhibir rasgos propios como "catástrofes naturales", "campesino", "identidad histórica", "identidad indígena" y "eje económico". El hecho de que el rasgo "catástrofes naturales" sea el más presente en las películas rodadas en la región del Bío-Bío durante el periodo estudiado, se entiende porque el terremoto del 2010 marcó un precedente importante en la zona, ya que los habitantes que vivieron esta historia de tragedia comparten un hecho en común que los identifica y acerca como comunidad. La mayor presencia del rasgo se entiende pues el catastro de películas es posterior al 2010, fecha de la tragedia. Por otro lado, el que los rasgos 
"indígena" y "campesino" sigan teniendo presencia en las películas rodadas en la zona está relacionado con el intercambio cultural que permite comprender la interacción socioétnica que caracteriza a la región del Bío-Bío, más todavía cuando dicha relación se encuentra en permanente estado de tensión a partir de narrativas en disputa por la hegemonía social (Gramsci, 1999), la cual se encuentra inclinada hacia los valores occidentales y neoliberales en Chile (Zúñiga, 2011).

Por otra parte, nos parece interesante destacar que un $36 \%$ de las películas no presentan ningún rasgo identitario de los identificados y construidos en este artículo en función de la región del Bío-Bío, con lo que dejan fuera algunos como el "capital cultural", "la cultura occidental" y la "diferenciación". Ello ocurre puesto que, desde esta perspectiva, los rasgos identitario-culturales son ampliamente flexibles y mutables en el tiempo (Baeza, 2000; Bauman, 2002), por cuanto lo aquí concluido representa un ejercicio académico que bajo ningún punto de vista podríamos replicar desde una dimensión holística; ello nos remite a la comprensión de la realidad social y de una memoria social (Halbwachs, 2004) que también es dúctil.

Si bien la mayoría de los filmes no dejan de lado los rasgos culturales y de diferenciación construidos en el artículo, con base en el estudio documental y teórico que tomó en cuenta aspectos históricos, culturales y económicos, creemos que aquellos son rasgos importantes para la identidad de la zona, pues la región del Bío-Bío es cuna de artistas invaluables a nivel internacional y zona de inspiración cultural para el país. De hecho, esto es particularmente interesante si se toma en cuenta que la comunidad, a través de los recursos estilísticos de las películas, reconoce el lugar donde se filmaron y su contexto, con lo que identifican la sociedad a la que pertenecen, sus miedos, alegrías y, en especial, su cultura (Prieto, 2010). Ello es consecuencia del periodo de tiempo analizado, pero en ningún caso es resolutorio respecto a definir una constante en la significación social e identitaria de la región en su relación con el cine, lo que puede inspirar futuros estudios del medio cinematográfico.

\section{Referencias}

Alvarado, C. (2018). Adiós a Latinoamérica. El hombre errante del Cine de Lisandro Alonso. Communication y Society, 31(3), 211-222.

Anderson, B. (2007). Comunidades imaginadas. Reflexiones sobre el origen y la difusión del nacionalismo: Fondo de Cultura Económica.

Arboleya. J. (2007). Colonialismo, neocolonialismo y socialismo. La Revolución del otro mundo. Ocean Sur. Azcona, J, (2016). Emigración y relaciones bilaterales. España-Chile (1810-2015). Editorial Dykinson.

Baena. G. (1988). Manual para elaborar trabajos de Investigación Documental. Editores Unidos Mexicanos.

Báez, F. (2017). Diseño institucional y neoliberalismo. El modelo chileno como resultado del quiebre unilateral del contrato social. Papers, 102(3), 449-476. 
Baeza. M. (2000). Los caminos invisibles de la realidad social. Ensayo de sociología profunda sobre los imaginarios sociales. Ril Editores.

Bachelard, G. (1928). Essai sur la connaissance approchée. J. Vrin.

Barker, C. (2003). Televisión, globalización e identidades culturales. Paidós.

Barth, F. (Comp.) (1976). Los grupos étnicos y sus fronteras. Fondo de Cultura Económica.

Basulto, O. (2014) Comunicación imaginada y turismo de intereses especiales (tesis doctoral). Universidad de Santiago de Compostela.

Bauman. Z. (2002). La cultura como praxis. Paidós.

Bazin, A. (1966). ¿¿ué es el cine? (2 ed.). Ediciones Rialp.

Berger, P., y Luckmann, T. (1976). La construcción social de la realidad. Amorrortu.

Boisier. S. (2006). La imperiosa necesidad de ser diferente en la globalización. El mercadeo territorial. La experiencia de las regiones chilenas. Revista Territorios, 15, 71 -85.

Camarero, G. (2002). La mirada que habla, cine e ideologías. Ediciones Akal S. A.

Casanueva, F. (1993). Los colegios más antiguos de Concepción. Revista Sociedad de Historia de Concepción, 7, 41-70.

Díaz. C. (1992). Métodos y Técnicas de Investigación. Eudema.

Di Chio, F. y Casetti, F. (2002). Cómo analizar un film. Paidós.

Durand. G. (1971). La imaginación simbólica. Amorrortu.

Fernández, S., Cordero, M. y Córdoba, A. (2002). Estadística descriptiva. Esic.

Fuente-Alba, F., y Basulto, O. (2018). Una epistemología del género documental para la memoria social en Chile. Cinta de Moebio, 61, 12-27.

Gallardo, F. (2008). Elementos para una antropología del Cine: los nativos en el cine ficción de Chile. Chungará, 40(especial), 317-325.

García Canclini, N. (2001). Culturas híbridas. Estrategias para entrar y salir de la modernidad. Paidós.

Geertz, C (1992). La interpretación de las culturas. Gedisa.

Giddens, A. (1999). Consecuencias de la modernidad. Alianza Editorial.

Giménez, G. (2005). La cultura como identidad y la identidad como cultura. Recuperado de: http://perio. unlp.edu.ar/teorias2/textos/articulos/gimenez.pdf

Gramsci, A. (1999). Cuadernos de la cárcel, Tomo 5. Edición crítica del Instituto Gramsci a cargo de Valentino Gerratana. (A. M. Palos, trad.). Ediciones Era.

Gubern, R. (1969). Historia del Cine. Anagrama.

Halbwachs, M. (2004). Los marcos sociales de la memoria. Anthropos.

Hall, S. (1981). Sociedad y comunicación de masas. Fondo de Cultura Económica. 
Hall, S. (1990). Cultural Identity and Diaspora. En J. Rutherford (Ed.), Identity. Lawrence and Wishart. Hernández-Sampieri. R., Fernández, C., y Baptista, L. (2006). Metodología de la investigación. McGrawHill.

Hernández-Sampieri R. y Mendoza, C. P. (2008). El matrimonio cuantitativo cualitativo: El paradigma mixto. En J. L. Álvarez Gayou (presidente), vi Congreso de Investigación en Sexología. Tabasco, México: Instituto Mexicano de Sexología, Universidad Juárez Autónoma de Tabasco.

Hoggart, R. (1970). La culture du pauvre. Minuit.

Ibáñez, J. (1985). Del algoritmo al sujeto: Perspectivas de la investigación social. Siglo XXI.

Larraín, J. (2001). Identidad chilena. LOM Ediciones.

Lipovetsky, G., y Serroy, J. (2009). La pantalla global. Cultura mediática y cine en la era hipermoderna. Anagrama.

Lozano J. (2018). Rasgos del cine histórico. Reflexión desde el cine colombiano. Comunicación y sociedad, 31, 221-241.

Kymlicka, W. (2007). Las odiseas multiculturales. Paidós Ibérica.

Kymlicka, W. (2010). Ciudadanía multicultural. Paidós Ibérica.

Martín-Barbero, J. (1998). De los medios a las mediaciones. Convenio Andrés Bello.

Mizón, L. (2001). Claudio Gay y la formación de la identidad cultural chilena. Editorial Universitaria.

Morales, J. y Maza, G. (2014). Idénticamente desigual: el cine imperfecto de Carlos Flores. Fidocs.

Montero, J. y Rodríguez, A. (2005). El cine cambia la historia. Editorial Rial S. A.

Pinto, I., González, S. y Munjin, V. (2018). Operación Termita: por una segunda línea en el cine chileno. Cuadernos.Info, 0(43), 71-83.

Prieto, A. (2010). La antigüedad a través del cine. Universitat de Barcelona.

Punch, K. (2005). Introduction to Social Research-Quantitative E Qualitative Approaches. Sage.

Raack, R. J. (1983). Historiography as cinematography: A prolegomenon to film work for historians. Journal of Contemporary History, 18(3), 411-438.

Rosenstone, A, (1997). El pasado en imágenes. El desafío del cine a nuestra idea de la historia. Ariel.

Tugendhat, E. (1996). Identidad: personal, nacional y universal, persona y sociedad. Ediciones LOM.

Valles. M. (1997). Técnicas cualitativas de investigación social. Reflexión metodológica y práctica profesional. Síntesis.

Varas, L. (2006). El cine chileno de exilio y la resistencia. CEME. Recuperado de http://www.archivochile. com/Dictadura_militar/muertepin8/muertepin8_0077.pdf

Villarroel, M. (2005). La voz de los cineastas: cine e identidad chilena en el umbral del milenio. Cuarto Propio.

Villarroel, M. (2012). Señales contra el olvido: cine chileno recobrado. Cuarto Propio.

Yáñez, N., y Molina, R. (comps.) (2011). Las aguas indígenas en Chile. Lom Ediciones. 
Witker, A. (2001). Identidad urbana en la región. Urbano, 4(4), 12-15.

Zúñiga, C. (2011). Modelo neoliberal y diseño sociopolítico. Comentarios sobre el caso chileno. Perspectivas de la comunicación, 4(1), 142-157. 